\title{
Comparative Study of Positron Emission Tomography /Computed Tomography and Whole-Body Bone Scanning for Detecting Bone Metastasis in Patients with Breast Cancer Mohamed Ahmed Youssef, Mohamed Fathy Dawoud, \\ Lamiss Mohamed Abdelaziz, Mostafa Hussein Elsheikh* \\ Radiodiagnosis Department, Faculty of Medicine, Tanta University \\ *Corresponding author: Mostafa Hussein Elsheikh, Mobile: (+20)01278011228, E-Mail: mo2006st@gmail.com
}

\begin{abstract}
Objective: the aim of this study was to compare the role of PET/CT \& bone scintigraphy in detection of bone metastasis in patients with breast cancer.

Patients and methods: The present study included 30 patients with breast cancer. Their ages ranged between $25 y e a r s$ and 65 years with mean age of 45 years old. All patients were subjected to full history taking, clinical breast examination, histopathology investigation, ${ }^{99 \mathrm{~m}} \mathrm{Tc}-\mathrm{MDP}$ Whole body bone scan, whole body positron emission tomography / computed tomography (FDG- PET/CT).

Results: on patient-based analysis in this study thirty patients were examined with bone scintigraphy and FDGPET/CT. only 24 (80\%) were detected by FDG-PET/CT had metastasis compared by only $18(60 \%)$ patients detected by bone scintigraphy. On lesion-based analysis in this study 71 lesions detected by FDG-PET/CT (positive 50 lesions $(70.42 \%$ ) - negative 21 lesions (29.58\%), compared by 62 lesions detected by bone scintigraphy (positive 43 lesions $(69.35 \%)$ - negative 19 lesions $(30.65 \%)$.

Conclusion: whole-body FDG-PET/CT is more sensitive and equally specific for the detection of bone metastases compared with bone scintigraphy. Both bone scintigraphy and FDG-PET/CT give false-positive results due to various common benign bone processes which are the most disadvantages of both modalities.
\end{abstract}

Keywords: PET/CT, Bone scintigraphy, bone metastasis, breast cancer.

\section{INTRODUCTION}

Bone is a common site for deposits in breast cancer patients, and most patients with advanced stages have osteoarthritis. Bone pain, fracture, spinal cord compression and bone marrow failure are common complications ${ }^{(\mathbf{1})}$.

The spine is a common site of metastasis due to its high content of red marrow and is highly vascularized. Peripheral lesions are commonly seen in young patients due to extensively distributed red marrow. Osseous metastases in cancer breast are mainly osteolytic and small percent are sclerotic or mixed lesions ${ }^{(2,3)}$.

For detection and evaluation of bone metastasis, ${ }^{99 \mathrm{~m}} \mathrm{Tc}$ labeled phosphate compound bone scintigraphy has been widely used because of its high sensitivity and easy evaluation of the whole skeletal system ${ }^{(4)}$.

Metabolic evaluation with positron emission tomography (PET) or fused PET and CT (PET/CT) has been recommended. 18 fluoro-deoxy-D-glucose (FDG) is the most commonly used PET tracer, FDG accumulation can therefore be detected in highly metabolic tissues, such as malignancies ${ }^{(5)}$.

PET can be used to investigate bone lesions, however, PET alone may lack anatomic detail; the fusion of PET/CT images improve its diagnostic ability for the metastatic disease ${ }^{(6)}$.

\section{AIM OF THE WORK}

The aim of this study is to compare the role of PET/CT \& bone scintigraphy in detection of bone metastasis in patients with breast cancer.

\section{PATIENTS AND METHODS}

Thirty patients were included in this study with histopathologically proven cancer breast referred from Oncology clinic to our institution with age ranging from 25 to 65 years and the mean age was 45 years +2 . The study was approved by the Ethics Committee of our institution; all patients signed an informed consent. The duration of the study extended from May 2016 to April 2018.

\section{Inclusion criteria}

Patients diagnosed to have breast cancer with suspected bone metastasis.

\section{Exclusion criteria}

- Pregnant women.

- Patients with chronic renal impairment if contrast media is used.

- Patients with previous allergy to contrast media.

Patients were subjected to the following:

a) Full history taking:

- Personal history.

- Complaint.

- Present history.

- Family history.

b) Clinical local breast examination.

c) Histopathology investigation.

d) ${ }^{99 \mathrm{~m}} \mathrm{Tc}-\mathrm{MDP}$ Whole body bones scan. 
e) Whole body positron emission tomography / computed tomography (FDG- PET/CT).

\section{Bone scintigraphy}

Bone scintigraphy was obtained with whole body scans on a dual head gamma camera (20 $\mathrm{cm} / \mathrm{min}$, body contouring). A bone scan requires no special preparation before the scan, apart from voiding of the bladder before examination with removal of jewelry or metallic objects.

The actual screening procedure takes about an hour. ${ }^{99 \mathrm{~m}} \mathrm{Tc}-\mathrm{MDP}$ bone scintigraphy was performed $4 \mathrm{hrs}$ after the intravenous injection of the tracer (5 $10 \mathrm{mci})$. Both anterior and posterior whole body planar images were simultaneously obtained with a dual-headed gamma camera.

\section{Risks of a Bone Scan}

A bone scan carries no greater risk than conventional X-ray. The tracers in the radioactive dye used in a bone scan produce very little radiation exposure. Even the risk of having an allergic reaction to the tracers is low.

However, the test may be unsafe for pregnant or breast-feeding women. There is a risk of injury to the fetus and of contaminating the breast milk.

\section{Interpretation of results}

Test results are considered normal when the dye is spread evenly throughout the body. This means that patient likely don't have a major bone problem.

Results are considered abnormal when the scan shows darker "hot spots" or lighter "cold spots" in the bones. Hot spots describe places where an excess of tracer has collected. Cold spots, on the other hand, are areas where the tracer didn't collect at all. Abnormal results can indicate that patient have a bone disorder, such as cancer or arthritis.

\section{Whole-body FDG-PET/CT}

Whole-body FDG-PET/CT-scan was obtained with a (Philips-GEMIN1 TP1G) device; All patients were instructed to fast 6 hours before receiving an intravenous application of 265+37 MBq FDG (184$340 \mathrm{MBq}$ ).

\section{Procedures for Whole-Body PET/CT Imaging with 18F-FDG}

The nuclear physician evaluates the history of the patient and sets the scan limits of the body. Chemotherapy of the patient was stopped one month before examination. The dose of the ${ }^{18}$ F-FDG was calculated based on the patient's weight

The patient is asked to fast for 6 hour prior to the scan, metallic items were removed from the patient, including dentures, belts, bracelets, and then the patient wears a gown. And IV catheter was inserted in the patient's arm for administration of ${ }^{18}$ F-FDG.

\section{Dosage Administration}

If the patient is diabetic, check the blood glucose level. If the level is $<200 \mathrm{mg} / \mathrm{dL}$, inject ${ }^{18} \mathrm{~F}$ FDG into the patient a dosage of $0.22 \mathrm{mCi} / \mathrm{kg}(8.1$ $\mathrm{MBq} / \mathrm{kg}$ ). If the level is $>200 \mathrm{~g}$, consult the physician. The cutoff value for glucose level varies with the institution.

The patient waits for 45-60 min after FDG administration and is instructed to remain quiet with minimal movement until the completion of the $\mathrm{PET} / \mathrm{CT}$ scan. The patient is asked to void prior to scanning.

\section{Scan}

The patient lies supine on the scan table with the head toward the gantry and is positioned by laser light. The patient's arms are positioned up (suspected thorax) or down (suspected head and neck) depending on the area to be scanned. Comfortable supports are provided for the head and neck, the arms, and the knees.

The table advances by computer control toward the gantry (first CT). Acquire a topogram to define axial range of the body for scanning. The patient is asked not to move, close eyes and breathe normally during this phase, When the area to be scanned is covered by the topogram, scanning is stopped.

Position the patient in the CT scan field and procure a spiral CT transmission scan that takes less than $1 \mathrm{~min}$. After the completion of the CT scan, the table is automatically advanced into the PET scanner with the patient in the scan field. The number of bed positions is automatically calculated from the axial range defined by the topogram. Data are acquired for a set time for each bed position. After the completion of the PET data acquisition for the last bed position, the patient is released.

\section{Statistical analysis}

Recorded data were analyzed using the statistical package for social sciences, version 20.0 (SPSS Inc., Chicago, Illinois, USA). Quantitative data were expressed as mean \pm standard deviation (SD). Qualitative data were expressed as frequency and percentage.

\section{The following tests were done:}

- Independent-samples t-test of significance was used when comparing between two means.

- Chi-square $\left(\mathrm{x}^{2}\right)$ test of significance was used in order to compare proportions between two qualitative parameters. 
- The confidence interval was set to $95 \%$ and the margin of error accepted was set to $5 \%$. The pvalue was considered significant as the following:

- Probability (P-value)

- P-value <0.05 was considered significant.

- P-value <0.001 was considered as highly significant.

- P-value >0.05 was considered insignificant.

\section{RESULTS}

Thirty patients were participated randomly in this study. The age of patients ranged from 25 to 65 years old, as shown in table (1).

Patient based comparison between bone scan and PET-CT with regard to positive and negative reading was significant $(\mathrm{p}<0.05)$ as presented in table (2).

Lesion-based Comparison between bone scan and PET-CT with regard to positive and negative reading was a significant as $(\mathrm{p}<0.05)$ as presented in table (3).

Lesion based Comparison between bone scan and PET-CT with regard to true positive and false positive reading was not significant as $(p>0.05)$ as presented in table (4).

Lesion based comparison between bone scan and PET-CT with regard to true negative and false negative reading was significant as $(\mathrm{p}<0.05)$ as presented in table (5) and (6).

Table (1): Illustrate patient age groups; it shows that the group (55-65) is the most affected by bone metastasis

\begin{tabular}{|c|c|}
\hline Age & bone metastasis \\
\hline $25-35$ & $4(13.33 \%)$ \\
\hline$>35-45$ & $7(23.33 \%)$ \\
\hline$>45-55$ & $9(30 \%)$ \\
\hline$>55-65$ & $10(33.33 \%)$ \\
\hline
\end{tabular}

Table (2): Patient based comparison between bone scan and PET-CT with regard positive and negative reading

\begin{tabular}{|c|c|c|c|c|c|}
\hline & \multirow{2}{*}{$\begin{array}{l}\text { Bone } \\
\text { scan }\end{array}$} & \multirow{2}{*}{$\begin{array}{l}\text { PET- } \\
\text { CT }\end{array}$} & \multicolumn{2}{|c|}{ Chi- square } \\
\hline & & & & $\mathbf{X}^{2}$ & $\begin{array}{c}p- \\
\text { value }\end{array}$ \\
\hline Positive & $\begin{array}{c}\text { NO } \\
\%\end{array}$ & $\begin{array}{c}18 \\
(60 \%)\end{array}$ & $\begin{array}{c}24 \\
(80 \%)\end{array}$ & \multirow{3}{*}{4.8} & \multirow{3}{*}{$0.028 *$} \\
\hline Negative & $\begin{array}{c}\text { NO } \\
\%\end{array}$ & $\begin{array}{c}12 \\
(40 \%)\end{array}$ & $\begin{array}{c}6 \\
(20 \%)\end{array}$ & & \\
\hline Total & $\begin{array}{c}\text { NO } \\
\%\end{array}$ & $\begin{array}{c}30 \\
(100 \%)\end{array}$ & $\begin{array}{c}30 \\
(100 \%)\end{array}$ & & \\
\hline \multicolumn{4}{|c|}{$\begin{array}{l}\text { NO: number } \% \text { : percentage } \\
\text { significant at } 0.05 \text { significance level. }\end{array}$} & \multicolumn{2}{|c|}{$* \boldsymbol{X}^{2}$-value was } \\
\hline
\end{tabular}

Table (3): Lesion based Comparison between bone scan and PET-CT with regard positive and negative reading

\begin{tabular}{|c|c|c|c|c|c|}
\hline & \multirow{2}{*}{ Bone scan } & \multirow{2}{*}{ PET-CT } & \multicolumn{2}{|c|}{ Chi- square } \\
\hline & & & & $\mathbf{X}^{2}$ & P-value \\
\hline Positive & $\begin{array}{l}\text { NO } \\
\%\end{array}$ & $\begin{array}{c}43 \\
(69.35 \%)\end{array}$ & $\begin{array}{c}50 \\
(70.42 \%)\end{array}$ & \multirow{3}{*}{18.47} & \multirow{3}{*}{$0.0001 *$} \\
\hline Negative & $\begin{array}{l}\text { NO } \\
\%\end{array}$ & $\begin{array}{c}19 \\
(30.65 \%)\end{array}$ & $\begin{array}{c}21 \\
(29.58 \%)\end{array}$ & & \\
\hline Total & $\begin{array}{l}\text { NO } \\
\%\end{array}$ & $\begin{array}{c}62 \\
(100 \%)\end{array}$ & $\begin{array}{c}71 \\
(100 \%)\end{array}$ & & \\
\hline
\end{tabular}

NO: number $\%$ : percentage $* \boldsymbol{X}^{2}$-value was significant at 0.05 significance level. p-value: Probability value

Table (4): lesion-based Comparison between bone scan and PET-CT with regard true positive and false positive reading

\begin{tabular}{|c|c|c|c|c|c|}
\hline & \multirow{2}{*}{$\begin{array}{l}\text { Bone } \\
\text { scan }\end{array}$} & \multirow[t]{2}{*}{ PET-CT } & \multicolumn{2}{|c|}{ Chi-square } \\
\hline & & & & $\mathbf{X}^{2}$ & $\begin{array}{c}p- \\
\text { value }\end{array}$ \\
\hline $\begin{array}{c}\text { True } \\
\text { Positive }\end{array}$ & $\begin{array}{c}\text { NO } \\
\%\end{array}$ & $\begin{array}{c}42 \\
(97.67 \%)\end{array}$ & $\begin{array}{c}48 \\
(96.00 \%)\end{array}$ & \multirow{3}{*}{0.04} & \multirow{3}{*}{0.834} \\
\hline $\begin{array}{c}\text { False } \\
\text { positive }\end{array}$ & $\begin{array}{c}\text { NO } \\
\%\end{array}$ & $\begin{array}{c}1 \\
(2.33 \%)\end{array}$ & $\begin{array}{c}2 \\
(4.00 \%)\end{array}$ & & \\
\hline Total & $\begin{array}{c}\text { NO } \\
\%\end{array}$ & $\begin{array}{c}43 \\
(100 \%) \\
\end{array}$ & $\begin{array}{c}50 \\
(100 \%) \\
\end{array}$ & & \\
\hline
\end{tabular}

NO: number $\%$ : percentage ${ }^{*} X^{2}$-value was significant at 0.05 significance level. p-value: Probability value

Table (5): lesion based Comparison between bone scan and PET-CT with regard true negative and false negative reading

\begin{tabular}{|c|c|c|c|c|c|}
\hline \multicolumn{2}{|c|}{} & \multirow{2}{*}{$\begin{array}{c}\text { Bone } \\
\text { scan }\end{array}$} & PET-CT & \multicolumn{2}{|c|}{ Chi- square } \\
\cline { 4 - 5 } \multicolumn{2}{|c|}{} & & & $\mathbf{X}^{\mathbf{2}}$ & $\begin{array}{c}\boldsymbol{p} \text { - } \\
\text { value }\end{array}$ \\
\hline $\begin{array}{c}\text { True } \\
\text { negative }\end{array}$ & $\begin{array}{c}\text { NO } \\
\mathbf{\%}\end{array}$ & $\begin{array}{c}12 \\
(63.16 \%)\end{array}$ & $\begin{array}{c}20 \\
(95.24 \%)\end{array}$ & & \\
\hline $\begin{array}{c}\text { False } \\
\text { negative }\end{array}$ & $\begin{array}{c}\text { NO } \\
\mathbf{\%}\end{array}$ & $\begin{array}{c}7 \\
(36.84 \%)\end{array}$ & $\begin{array}{c}1 \\
(4.76 \%)\end{array}$ & 0.04 & 0.03 \\
\cline { 1 - 3 } Total & $\begin{array}{c}\text { NO } \\
\mathbf{\%}\end{array}$ & $\begin{array}{c}19 \\
(100 \%)\end{array}$ & $\begin{array}{c}21 \\
(100 \%)\end{array}$ & & \\
\hline
\end{tabular}

NO: number $\quad \%$ : percentage $\quad * \boldsymbol{X}^{2}$-value was significant at 0.05 significance level. $\boldsymbol{p}$-value: Probability value

Table (6): sensitivity, specificity and accuracy based on lesions seen by at least one of both modalities

\begin{tabular}{|c|c|c|}
\hline & Bone scan & PET-CT \\
\hline Sensitivity & $85.71 \%$ & $97.96 \%$ \\
\hline Specificity & $92.31 \%$ & $90.91 \%$ \\
\hline Accuracy & $87.10 \%$ & $95.77 \%$ \\
\hline
\end{tabular}

NO: number $\%$ : percentage $* \boldsymbol{X}^{2}$-value was significant at 0.05 significance level. $\quad \boldsymbol{p}$-value: Probability value 


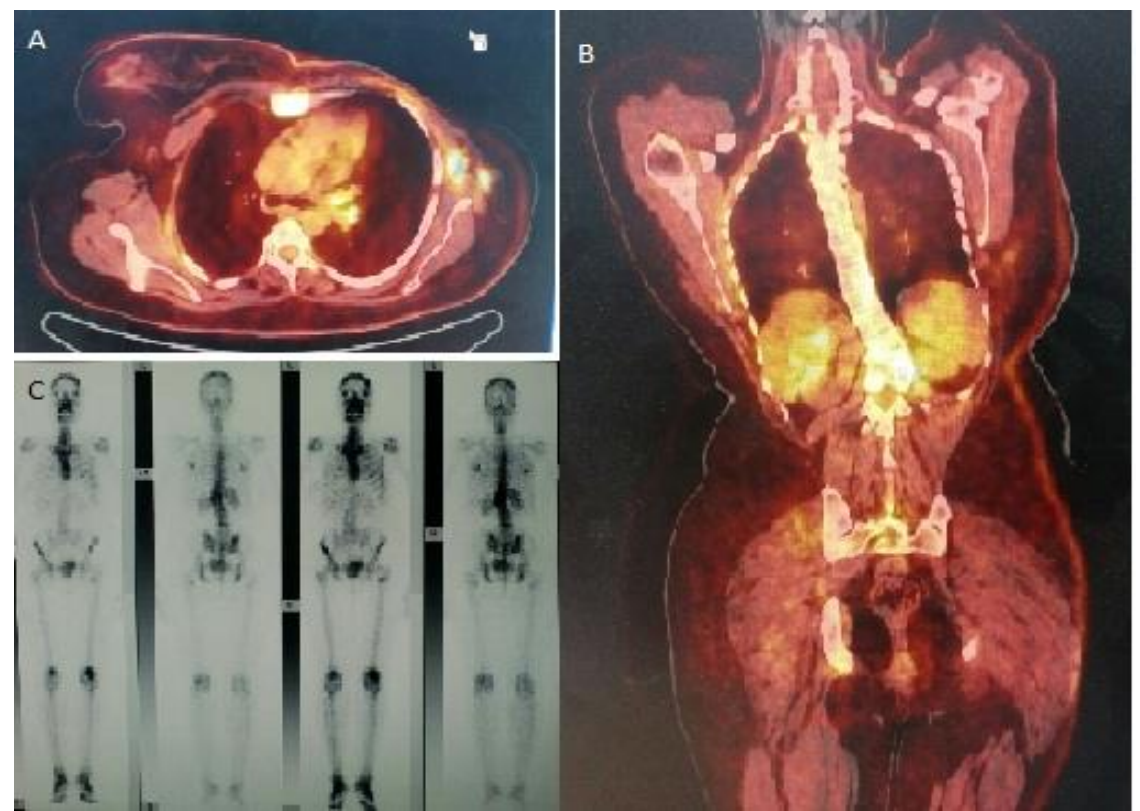

Fig.1: 40 year- old- female patient with cancer breast underwent left mastectomy, received chemotherapy and radiotherapy.(A) axial PET/CT image, (B) coronal PET/CT image show metabolically active FDG avid predominantly lytic lesions are seen at the sternum, left $7^{\text {th }}$ rib, left side of D7vertebrae. (C) bonescan images showarea of increased uptake is seen at the dorso-lumber region associated with scoliotic deformity.

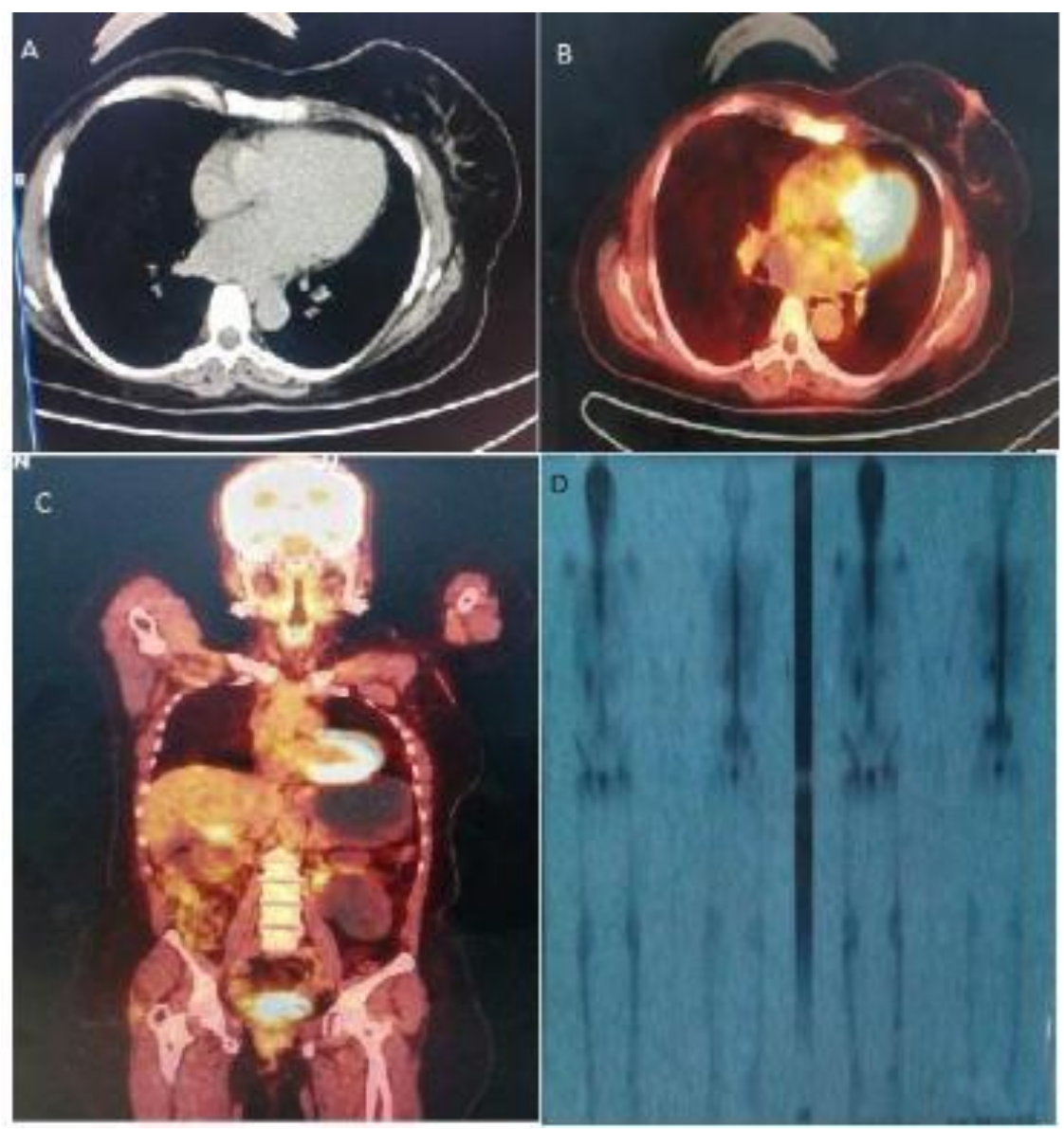

Fig. 2: 52 year- old - female patient with right breast cancer underwent right mastectomy and received chemotherapy. (A) axial CT image, (B) axial PET/CT image, (C) coronal PET/CT image, increased metabolic activity as well as extent of destruction of the metabolically active FDG avid sternum bony deposit (maximum SUV 6). (D) Bone scan images show free from bone metastasis. 


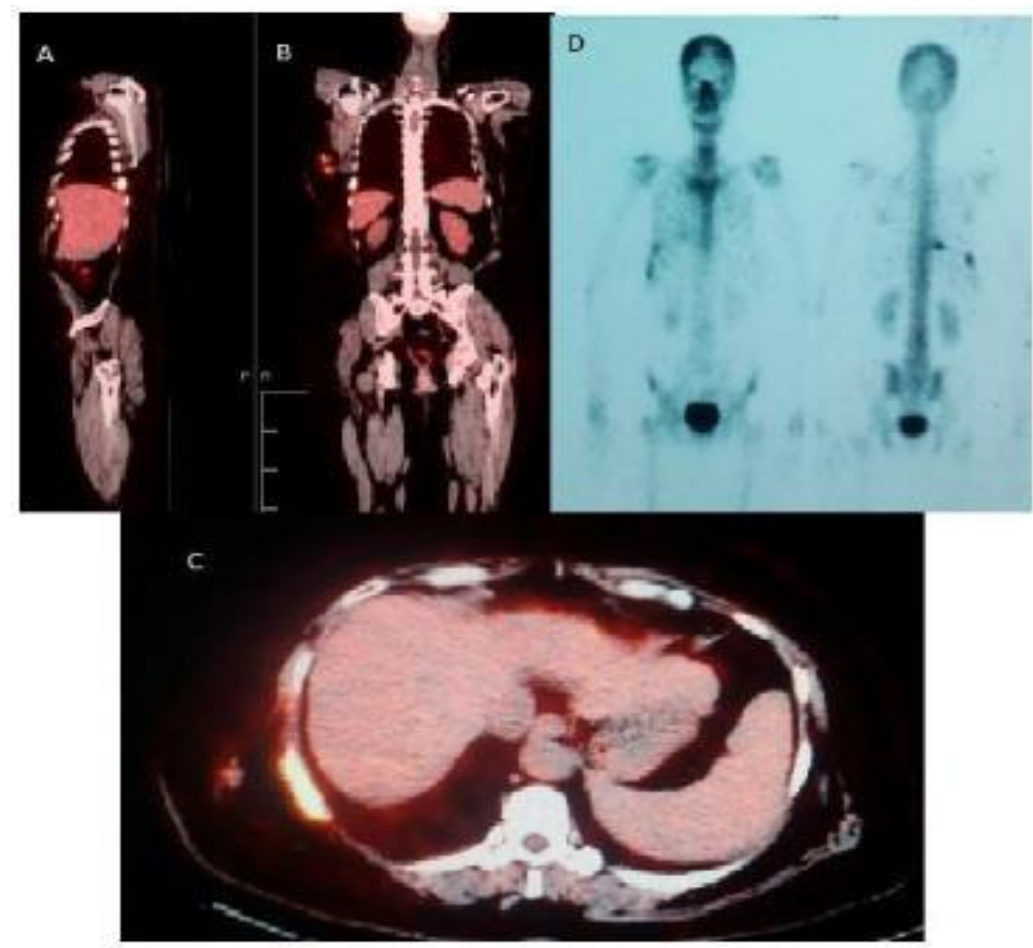

Fig 3: 56 year - old - female with right breast cancer underwent modified radical right mastectomy and received chemotherapy. (A) Sagittal PET/CT image, (B) Coronal PET/CT image, (C) Axial PET/CT image, show metabolically active FDG avid is seen involving the right $2^{\text {th }}, 9^{\text {th }}, 10^{\text {th }}$ ribs (max. SUV 6.9). (D) Bone scan images show two focal spots of active tracer uptake are seen at right $9^{\text {th }}$ rib.

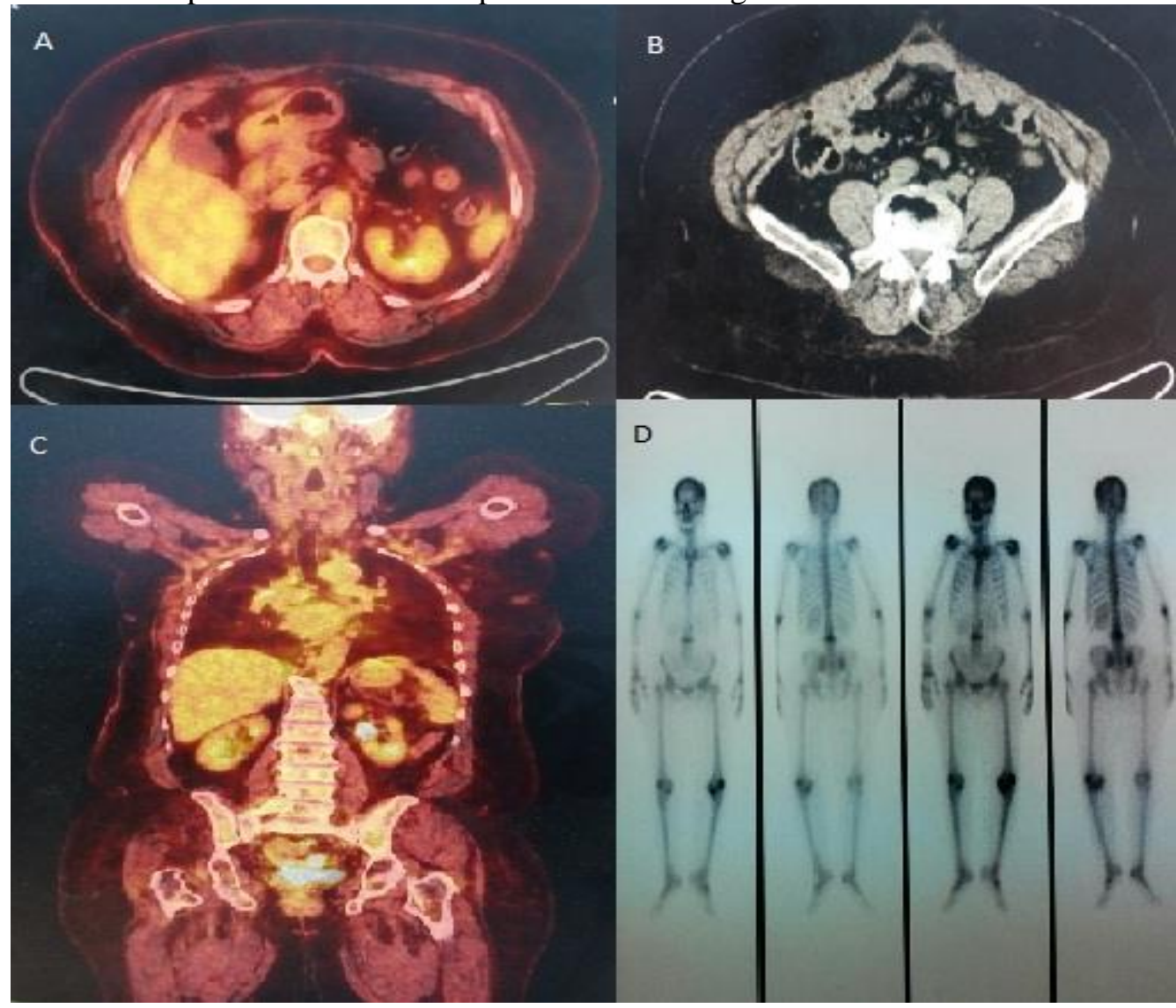

Fig 4: 65 year- old - female patient with right breast cancer underwent right mastectomy and received chemotherapy and radiotherapy. (A) axial PET/CT image, (B) Axial CT image, (C) coronal PET/CT image show no metabolically active FDG-avid bone metastatic deposits. Osteoporotic osseous texture with reduced height of L3 vertebral body. (D) Bone scan images show an expanding spot of enhanced tracer uptake is seen at $\mathrm{L} 3$ vertebrae. 


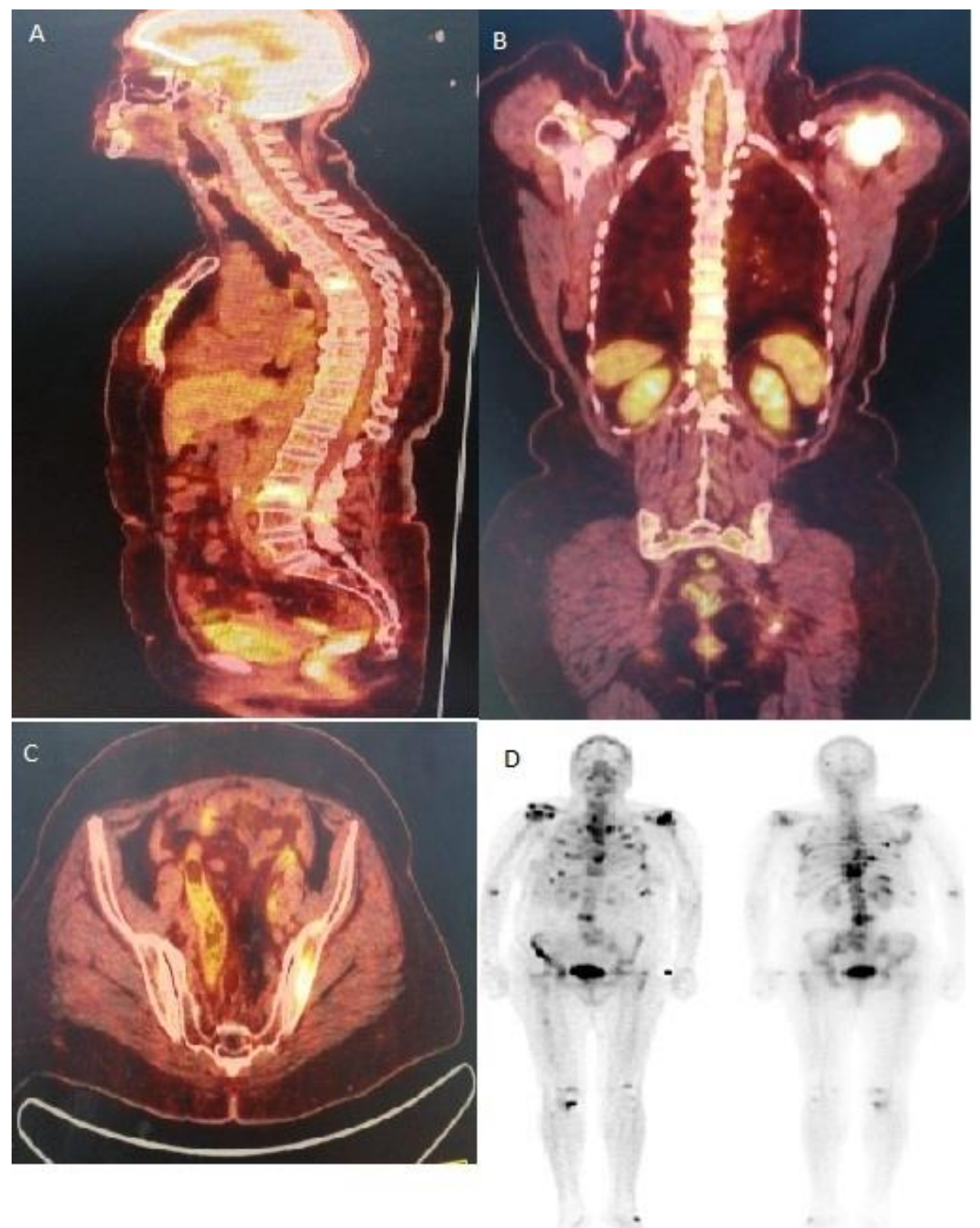

Fig 5: 61 year - old - female patient with right breast cancer performing PET/CT and bone scan for pretherapeutic assessment. (A) Sagittal PET/CT image, (B) Coronal PET/CT image, (C) Axial PET/CT image show FDG-avid multiple widespread mixed osteolytic and sclerotic lesions involving the whole spine, sternum, clavicles, humeri, scapulae, ribs, sacrum, pelvic bones and upper femora as well as right tibia. (D) Bone scan images show multiple focal spots of active tracer uptake is seen at multiple vertebrae, scapula, multiple ribs, pelvic bones right tibia, humeri, clavicle and sternum.

\section{DISCUSSION}

Cancer breast is the most common malignant neoplasm found in women, it representing $18.9 \%$ of total cancer patients all over the world ${ }^{(7)} .{ }^{99} \mathrm{Tc}$ labeled phosphate compound bone scintigraphy and positron emission tomography (PET) using 2-[18F]fluoro-2-deoxy-D-glucose (18FDG-PET/CT) were known to be a powerful tools for the detection of metastatic or recurrent lesions in different malignant neoplasm, and also useful for the detection of bone metastasis ${ }^{(\mathbf{8}, \mathbf{9})}$.
The most common affected age group in our study was ranged from 55 to 65 years old (33.33\%), this in agree with the study of Carole $\boldsymbol{e t}$ al. ${ }^{(\mathbf{1 0})}$ who reported that mean age group ranged from 50 to 64 years old (34.37\%), and the median age reported in the study of Zhang $\boldsymbol{e t}$ al. ${ }^{(\mathbf{1 1 )})}$ was 57 years old.

On patient-based analysis: in our study thirty patients were examined in this study with bone scintigraphy and FDG-PET/CT. only $24(80 \%)$ were detected by FDG-PET/CT had metastasis compared by only $18(60 \%)$ patients detected by bone scintigraphy, while in the study of Steffen $\boldsymbol{e t}$ al. ${ }^{(\mathbf{1 2})}$ 
twenty nine patients was examined by both modalities, only $21(72 \%)$ patients was detected by FDG-PET/CT to have bone metastasis, compared by $18(62.07 \%)$ was detected by bone scintigraphy ${ }^{(\mathbf{1 2})}$.

On lesion based analysis: in our study 71 lesions detected by FDG-PET/CT (positive 50 lesions $(70.42 \%)$ - negative 21 lesions $(29.58 \%)$, compared by 62 lesions detected by bone scintigraphy (positive 43 lesions $(69.35 \%)$ negative 19 lesions (30.65\%), while in the study of Steffen et $\boldsymbol{a l l}^{\left({ }^{(12)}, 84\right.}$ lesions detected by FDGPET/CT ( positive 73 lesions $(86.90 \%$ ) - negative 11 lesions (13.10\%), compared by 97 lesions detected by bone scintigraphy ( positive 56 lesions $(57.73 \%$ ) - negative 41 lesions (42.27\%).

In this study both FDG-PET/CT and bone scintigraphy had good specificity as it recorded (90.91\%) for FDG-PET/CT while it was $(92.31 \%)$ for bone scintigraphy, while the FDG-PET/CT was more sensitive $(97.96 \%)$ than bone scintigraphy $(85,7 \%)$, these results compared by the study of Liu et $\boldsymbol{a l} .^{(13)}$ which found on lesion basis a better sensitivity for FDG-PET/CT (87\% vs. 67\%) and slightly better specificity of bone scintigraphy $(99 \%$ vs.92\%) was reported for the detection of bone metastases in breast cancer patients.

Also comparing our study results as regard sensitivity and specificity with the study of Steffen

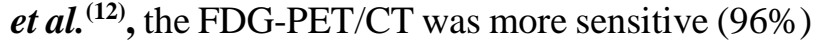
than bone scintigraphy $(76 \%)$ while bone scintigraphy was slightly more specific $(95 \%)$ than FDG-PET/CT (92\%).

Mahner et al. $^{(14)}$ reporting that PET alone, according to lesion basis, has no advantage compared to bone scintigraphy giving similar sensitivity (89\% and $83 \%$ ) specificity (92\% and $89 \%$ ) for bone scintigraphy and FDG-PET.

FDG-PET/CT appears to be slightly advantageous through a better sensitivity on a lesionbasis. However, this does not replacing the bone scintigraphy as a routine tool, since no significant difference between FDG-PET/CT and bone scintigraphy on a patient basis was found ${ }^{(\mathbf{1 5}) .}$

In conclusion, FDG-PET/CT is more sensitive and equally specific than bone scintigraphy for the detection of bone metastases in cancer patients. FDG-PET/CT being increasingly performed for whole-body staging or neoadjuvant therapy this may obviate additional bone scans ${ }^{(\mathbf{1 2})}$.

\section{REFERENCES}

1. James JJ, Evans AJ, Pinder SE et al. (2003): Bone metastases from breast carcinoma: histopathological
- radiological correlations and prognostic features. $\mathrm{Br}$ J Cancer, 89(4):660-65.

2. Hamaoka T, Madewell JE, Podoloff DA et al. (2004): Bone imaging in metastatic breast cancer. J Clin Oncol., 22(14): 2942-53.

3. Cook GJ and Fogelman I (2001): Skeletal metastases from breast cancer: imaging with nuclear medicine. Semin Nucl Med., 29:69-79.

4. Jacobson AF (1996): Bone scanning in metastatic disease. In: Skeletal Nuclear Medicine, Collier BD Jr, Fogelman I, Rosenthall L, eds. St. Louis; Mosby, pp87-123.

5. Costelloe CM, Rohren EM, Madewell JE et al. (2009):Imaging bone metastases in breast cancer: techniques and recommendations for diagnosis. Lancet Oncol., 10: 606-14.

6. Veit-Haibach $\mathrm{P}$, Antoch $\mathrm{G}$, Beyer $\mathrm{T}$ et al. (2007):FDG-PET/CT in restaging of patients with recurrent breast cancer: possible impact on staging and therapy. Br J Radiol., 80: 508-15.

7. Ravdin PM, Cronin KA, Howlader N et al. (2007): The decrease in breast-cancer incidence in 2003 in the United States. N Engl J Med., 356:1670.

8. Jacobson AF. Collier BD JR, Fogelman I et al. (1996): Bone scanning in metastatic disease. In: Skeletal Nuclear Medicine, Mosby, pp87-123.

9. Dose J, Bleckmann C, Bachmann S et al. (2002): Comparison of fluorodeoxyglucose positron emission tomography and "conventional diagnostic procedures" for the detection of distant metastases in breast cancer patients. Nucl Med Commun., 23:857864.

10. Carol D, Jiemin M, Leah B et al. (2013): Breast cancer statics.CA Cancer J Clin., 64(1):52-62.

11. Zhang L, Lihua C, Qiao $X$ et al. (2015):A comparative study of $18 \mathrm{~F}$-fluorodeoxyglucose positron emission tomography/computed tomography and 99mTc-MDP whole-body bone scanning for imaging osteolytic bone metastases. BMC Medical Imaging, 15:7.

12. Steffen H, Till H, Sherko $K$ et al. (2011): Comparison of FDG-PET/CT and bone scintigraphy for detection of bone metastases in breast cancer, Acta Radiologica, 52: 1009-14.

13. Mahner S, Schirrmacher S, Brenner $W$ et al. (2008): Comparison between positron emission tomography using 2-(fluorine-18)fluoro-2-deoxy-Dglucose, conventional imaging and computed tomography for staging of breast cancer. Ann Oncol., 19:1249-54.

14. Gallowitsch HJ, Kresnik E, Gasser J et al. (2003): F-18 fluorodeoxyglucose positron-emission tomography in the diagnosis of tumor recurrence and metastases in the follow-up of patients with breast carcinoma: a comparison to conventional imaging. Invest Radiol., 38: 250-6.

15. Costelloe CM, Rohren EM, Madewell JE et al. (2009): Imaging bon metastases in breast cancer: techniques and recommendations for diagnosis. Lancet Oncol., 10:606-14. 